\title{
Pengaruh Lingkungan Kerja dan Motivasi Kerja Terhadap Semangat Kerja PT. Alkonusa Teknik Interkon Surabaya
}

\author{
Amrul Khakim¹,Moch Munir Rachman² \\ Fakultas Ekonomi Prodi Manajemen dan Bisnis Universitas PGRI Adi Buana, Surabaya \\ amrulkhakim322@gmail.com
}

\begin{abstract}
Abstrak
Penelitian yang akan dilakukan ini guna mengetahui apakah ada faktor yang mempengaruhi dari kinerja karyawan PT. Alkonusa Teknik Interkon Surabaya. Dimana faktor tersebut memliki dua variabel yaitu lingkungan kerja dan motivasi kerja Karyawan yang memiliki motivasi yang besar dalam bekerja bertujuan untuk perusaahan di PT. Alkonusa Teknik Interkon Surabaya, pengambilan data yang digunakan untuk mengukur menggunakan alat bantu SPSS. Teknik sampling digunakan untuk dipakai yakni metode kuisioner, observasi, dokumentasi. Dalam penelitian ini terdapat beberapa teknik pengujian yang terdiri dari "uji instrumen, uji asumsi klasik dan uji regresi linier berganda". Hasil uji regresi linier berganda menunjukkan koefisien regresi pada variabel X1 0,379 dan variabel X2 0,622. Hasil Uji T dapat disimpulkan bahwa nilai lingkungan kerja (X1) t-hitung = 4.226 dan nilai sig. 0,000. Motivasi kerja (X2) t-hitung $=8.098$ dan nilai sig. 0,000 . Sedangkan hasil Uji F menunjukkan hasil nilai variabel lingkungan kerja dan motivasi kerja $\mathrm{F}$ simultan 50.270 dan nilai sig. 0,000. Dari hasil penelitian dapat disimpilkan bahwa lingkungan kerja dan motivasi kerja berpengaruh terhadap semangat kerja karyawan yang berada di PT. Alkonusa Teknik Interkon, Surabaya.
\end{abstract}

Kata kunci : Lingkungan Kerja, Motivasi Kerja, dan Semangat Kerja

\begin{abstract}
Abstrack
This research will be conducted to determine whether there are factors that influence the performance of employees of PT. Alkonusa Surabaya Interconnect Engineering. Where these factors have two variables, namely the work environment and work motivation Employees who have great motivation in working to aim at the company at PT. Alkonusa Surabaya Interconnect Engineering, data retrieval used to measure using SPSS tools. The sampling technique used to use the questionnaire method, observation, documentation. In this study there are several testing techniques consisting of "test instruments, test classic assumptions and multiple linear regression tests". The results of multiple linear regression test showed the regression coefficient on the X1 variable 0,379 and $X 2$ variable 0,622 . $T$ test results can be concluded that the value of the work environment (X1) $t$-count $=4.226$ and the value of sig. 0,000. Work motivation (X2) $t$-count $=8098$ and sig. 0,000 . While the $F$ Test results show the results of the work environment variable values and the simultaneous work motivation of $F, 2,270$ and sig values. 0,000. From the results of the study it can be concluded that the work environment and work motivation affect the morale of employees who are at PT. Alkonusa Interkon Engineering, Surabaya
\end{abstract}

Keywords: Work Environment, Work Motivation, and Work Spirit 


\section{PENDAHULUAN}

Latar Belakang

Suatu organisasi atau perusahaan ditentukan beberapa faktor, yakni sumber daya manusia, (sarana prasarana pendukung dan karyawan). Dalam perencanaan sumber daya manusia yang masih menjadi masalah bagi perusahaan meliputi dari program penyesuaian pada karyawan guna memajukan perusahaan atau organiisasi. Sebagus dan sebanyak apapun fasilitas yang ada dalam perusahaan, tanpa adannya sumber daya yang mempuni, baik kuantitas maupun kualitas, maka dapat menghasilkan organisasi atau perusahaan tersebut tidak dapat berhasil mewujudkan tujuan perusahaan yang lebih baik..

Kualitas karyawan tidak terlepas dari lingkungan kerja dan motivasi didalam instansi tersebut. Kualitas sumber daya manusia bisa dinilai dari semangat kerja seorang pegawai dalam menyelesaikan pekerjaan di suatu perusahaan atau instansi..

Adanya faktor lingkungan khususnya lingkungan kerja fisik misalkan bagian cat tembok yang kurang baik, baik itu dalam ruangan maupun diluar ruangan, minimnya cahaya di ruangan, selanjutnya transportasi oprasioanal perusahaan yang tidak dapat dipakai dan butuh di service. Hal ini bisa berakibat kurangnya semangat kerja karyawan di perusahaan. Dimana perusaahan dituntut untuk memperbaiki permasalahan guna meningkatkan lingkungan perusahaan yang lebuh baik.

\section{TELAAH PUSTAKA}

\section{Landasan Teori}

\section{Lingkungan Kerja}

Lingkungan kerja yaitu semua hal yang ada di sekeliling karyawan yang berpengaruh terhadap dirinya dalam melakukan perkerjaan yang sedang dikerjakan. Adapun beberapa indikator pada variabel lingkungan kerja yakni persoalan kebersihan, persoalan keamanan perusahaan, persoalan suara gaduh dan persoalan penerangan.

\section{Motivasi Kerja}

Motivasi kerja harus ada dalam diri seorang pegawai. Walaupun fasilitas diberikan oleh perusahaan memadai serta kualitas kemampuan yang tinggi jika tidak didukung dengan motivasi yang baik maka suatu pekerjaan itu pun tidak akan menghasilkan sesuai dengan apa yang diinginkan

Adapun beberapa indikator yang terdapat pada variabel motivasi kerja yakni sosial, penghargaan diri dan aktuluasi dirii.

\section{Semaangat Kerja}

Semangat kerja yaitu suatu kondisi atau suasana dalam bekerja yang menunjukkan keinginan dalam menjalankan suatu pekerjaan dan mendorng seorang karyawan untuk bekerja giat dan cepat .

Adapun beberapa indikator yang terdapat paada variabel semangat kerja 
yakni gaji yang sesuai, penempatan pegawai pada posisi yang tepat, pemberian penghargaan, fasilitas.

\section{Kerangka Konseptual}

Kerangka konseptual adalah uraian yang mengartikan suatu variabel dan hubungan yang menjelaskan rumasan masalah berdasarkan teori yang sudah ada. Dengan dibuatnya kerangka konseptual bisa mempermudah peneliti untuk menjelaskan garis besar permasalahannya, dalam hal ini kerangka konseptul bisa dilihat pada gambar di bahawah ini:

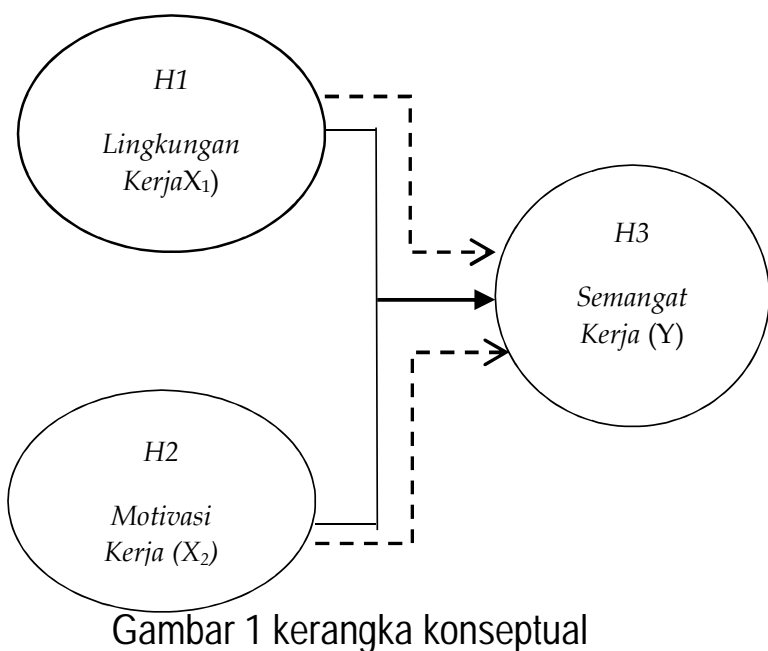

Hipotesis

Berdasarkan tujuan dan manfaat serta penjabaran teori, hipotesis yang dapat digunakan untuk penelitian ini yaitu:

H1 : Lingkungan kerja berpengaruh terhadap semangat karyawan PT. Alkonusa Teknik Interkon Surabaya

H2 : Motivasi kerjaberpengaruh terhadap semangat kerja karyawan PT. Alkonusa Teknik Interkon Surabaya
H3 : Lingkungan kerja dan motivasi kerja berpengaruh terhadap semangat kerja karyawan PT. Alkonusa Teknik Interkon Surabaya

\section{METODE PENELITIAN}

\section{Rancangan Penelitian}

Menurut Sugiono (2015) penelitian yaitu adanya upaya unyuk menghasilkan data untuk tujuan dan kepemtingan tertentu. Penelitian adalah suatu analisis yang berdasarkan pada ciri keilmuan yang masuk akal, empiris, dan sistematis. Dimana penelitian pengukuran datanya melalui perhitungan ilmiiah atau menyebarkan kuisioner kepada responden dengan mengambil beberapa sampel responden dalam suatu perusahaan atau organisasi .

Penelitian kuantitatif bertujuan mengalisis teori, mencari kebenaran, dan menunjukkan pengaruh pada variabel..

\section{Populasi, Sampel, dan Teknik Pengambilan Sampel}

Sampel yang ditujuh seluru pegawai PT. Alkonusa Teknik Interkon Surabaya yang berjumlah 69 karyawan.

Teknik nonprobability ini memiliki banyak jenis dan menggunakan jenis yaitu sampling jenuh atau sensus.

\section{Alat Pengumpulan Data}

1. Kuisioner

2. Observasi

3. Dokumentasi

\section{HASIL PEELITIAN DAN PEMBAHASAN}




\section{a. Uji Validitas}

Untuk pengukuran valid dan tidaknya kuisioner dari menguji data yang diperoleh juga bisa juga dilakukan dengan melalui uji validitas. Untuk mengetahui hasil nilai dapat menggunakan progam (SPSS).

Tabel 1

Uji Validitas

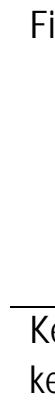

Fisiologis (X2.1)

$1 \quad 0,38 \quad 0.23 \quad$ Valid

65

$2 \quad 0,39 \quad 0.23 \quad$ Valid

65

$\begin{array}{llll}3 & 0,55 & 0.23 & \text { Valid }\end{array}$

Keamanan dan

keselamatan (X2.2)

$\begin{array}{cccc}1 & 0,49 & 0.23 & \text { Valid } \\ & 8 & 5 & \end{array}$

$2 \quad 0,47 \quad 0.23 \quad$ Valid

$\begin{array}{llll}3 & 0,58 & 0.23 & \text { Valid }\end{array}$

\begin{tabular}{ccccc}
\hline Indikator & It & Corr & Nilai & Keter \\
& e & elati & Kriti & anga \\
& $m$ & on & $s$ & $n$
\end{tabular}

\begin{tabular}{ccccc}
\hline Indikator & It & Corr & Nilai & Keter \\
& e & elati & Kriti & anga \\
& $m$ & on & $\mathrm{s}$ & $\mathrm{n}$
\end{tabular}

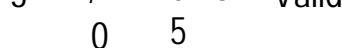

Lingkungan Kerja (X1)

\begin{tabular}{|c|c|c|c|c|c|c|c|c|c|}
\hline \multirow[t]{3}{*}{$\begin{array}{l}\text { Pengaturan penerangan } \\
\text { (X1.1) }\end{array}$} & 1 & $\begin{array}{c}0,44 \\
2\end{array}$ & $\begin{array}{c}0.23 \\
5\end{array}$ & Valid & & 3 & $\begin{array}{c}0,63 \\
4 \\
\end{array}$ & $\begin{array}{l}0.23 \\
5\end{array}$ & Valid \\
\hline & 2 & 0,62 & $\begin{array}{l}0 \\
0.23 \\
5\end{array}$ & Valid & Penghargaan (X2.4) & 1 & $\begin{array}{c}0,77 \\
7\end{array}$ & $\begin{array}{l}0.23 \\
5\end{array}$ & Valid \\
\hline & 3 & $\begin{array}{c}0,85 \\
6\end{array}$ & $\begin{array}{l}0.23 \\
5\end{array}$ & Valid & & 2 & $\begin{array}{c}0,64 \\
1\end{array}$ & $\begin{array}{l}0.23 \\
5\end{array}$ & Valid \\
\hline \multirow[t]{3}{*}{$\begin{array}{l}\text { Pengontrolan suara } \\
\text { gaduh (X1.2) }\end{array}$} & 1 & $\begin{array}{c}0,50 \\
2\end{array}$ & $\begin{array}{l}0.23 \\
5\end{array}$ & Valid & & 3 & $\begin{array}{c}0,37 \\
9\end{array}$ & $\begin{array}{l}0.23 \\
5 \\
\end{array}$ & Valid \\
\hline & 2 & $\begin{array}{c}0,70 \\
1\end{array}$ & $\begin{array}{l}0.23 \\
5\end{array}$ & Valid & Aktuluasi diri (X2.5) & 1 & $\begin{array}{c}0,68 \\
6\end{array}$ & $\begin{array}{l}0.23 \\
5 \\
0.23\end{array}$ & Valid \\
\hline & 3 & $\begin{array}{c}0,75 \\
7\end{array}$ & $\begin{array}{l}0.23 \\
5\end{array}$ & Valid & & $\begin{array}{l}2 \\
3\end{array}$ & $\begin{array}{c}0,78 \\
7\end{array}$ & $\begin{array}{l}0,23 \\
5 \\
0,23\end{array}$ & $\begin{array}{l}\text { Valid } \\
\text { Valid }\end{array}$ \\
\hline \multirow[t]{3}{*}{$\begin{array}{l}\text { Pengaturan kebersihan } \\
\text { tempat kerja (X1.3) }\end{array}$} & 1 & $\begin{array}{c}0,69 \\
7\end{array}$ & $\begin{array}{l}0.23 \\
5\end{array}$ & Valid & & & $\begin{array}{c}0,81 \\
1\end{array}$ & 5 & \\
\hline & 2 & $\begin{array}{c}0,67 \\
3\end{array}$ & $\begin{array}{l}0.23 \\
5\end{array}$ & Valid & $\begin{array}{l}\text { Semangat kerja }(\mathrm{Y}) \\
\text { Gaji yang sesuai }(\mathrm{Y})\end{array}$ & 1 & 0,92 & $\begin{array}{l}0.23 \\
5\end{array}$ & Valid \\
\hline & 3 & $\begin{array}{c}0,72 \\
9\end{array}$ & $\begin{array}{l}0.23 \\
5\end{array}$ & Valid & & 2 & 0,45 & 0.23 & Valid \\
\hline \multirow[t]{3}{*}{$\begin{array}{l}\text { Pengaturan keamana } \\
\text { tempat kerja }(\mathrm{X} 1.4)\end{array}$} & 1 & $\begin{array}{c}0,74 \\
3 \\
0,69\end{array}$ & $\begin{array}{l}0.23 \\
5 \\
0.23\end{array}$ & Valid & & 3 & $\begin{array}{c}3 \\
0,39 \\
3\end{array}$ & $\begin{array}{l}0.23 \\
5 \\
\end{array}$ & Valid \\
\hline & 2 & 4 & 5 & & \multirow{3}{*}{$\begin{array}{l}\text { Penempatan pegawai } \\
\text { pada posisi yang tepat } \\
(\mathrm{Y})\end{array}$} & 1 & $\begin{array}{c}0,92 \\
9\end{array}$ & $\begin{array}{l}0.23 \\
5\end{array}$ & Valid \\
\hline & 3 & $\begin{array}{c}0,77 \\
4\end{array}$ & $\begin{array}{l}0.23 \\
5\end{array}$ & Valid & & 2 & $\begin{array}{c}0,92 \\
9\end{array}$ & $\begin{array}{l}0.23 \\
5\end{array}$ & Valid \\
\hline Motivasi (X2) & & & & & & 3 & $\begin{array}{c}0,32 \\
9\end{array}$ & $\begin{array}{l}0.23 \\
5\end{array}$ & Valid \\
\hline
\end{tabular}




\begin{tabular}{lccll} 
& 4 & 0,25 & 0.23 & Valid \\
& & 3 & 5 & \\
\hline Pemberian penghargaan & 1 & 0,92 & 0.23 & Valid \\
$(\mathrm{Y})$ & 9 & 5 & \\
& 2 & 0,92 & 0.23 & Valid \\
& 9 & 5 & \\
& 3 & 0,45 & 0.23 & Valid \\
& 3 & 5 & \\
& 4 & 0,39 & 0.23 & Valid \\
& 3 & 5 & \\
& 5 & 0,92 & 0.23 & Valid \\
& & 9 & 5 & \\
\hline Fasilitas (Y) & 0,32 & 0.23 & Valid \\
& 9 & 5 & \\
& 2 & 0,39 & 0.23 & Valid \\
& 3 & 5 & \\
& 3 & 0,92 & 0.23 & Valid \\
& 9 & 5 &
\end{tabular}

tabel 1 hasil uji validitas memperlihatkan correlation setiap indikator variabel Lingkungan kerja, Motivasi kerja, dan semangat kerja lebih besar dari 0,235.

\section{b. Uji reabilitas}

Reliabilitas suatu indikator dan kuesioner dapat dilihat dari nilai cronbachs alpha ${ }^{*} \alpha$, yaitu apabila nilai cronbachs alpha * $\alpha$ lebih besar (>) 0,6 maka indikator atau kuesioner adalah reliabel, sedangkan apabila nilai cronbachs alpha *a lebih kecil (<) 0,6 maka indikator atau kuesioner tidak reliabel.

\section{Tabel 2}

Hasil Uji Reliabilitas

tabel 2 hasil perhitungan yakni

Alpha Cornbach > 0,6 maka bisa menunjukkan keterangan pernyataan

\begin{tabular}{cccc}
\hline Variabel & $\begin{array}{c}\text { Cronb } \\
\text { ach's } \\
\text { Alpha }\end{array}$ & $\begin{array}{c}\text { Nil } \\
\text { Krit } \\
\text { is }\end{array}$ & $\begin{array}{c}\text { Keteran } \\
\text { gan }\end{array}$ \\
\hline Lingkungan Kerja & 0,895 & 0,6 & Reliabel \\
Motivasi Kerja & 0,871 & 0,6 & Reliabel \\
Semangat Kerja & 0,910 & 0,6 & Reliabel \\
& & & \\
\hline tersebut reilebel.. & & &
\end{tabular}

\section{Uji Asumsi Klasik}

\section{Uji Normalitas}

Uji normalitas untuk menganalisis apakah dalam suatu model regeresi, variabel bebas, variabel terikat atau keduanya memiliki distribusi normal atau tidak. Untuk mempermudah dalam perhitungan dengan menggunakan SPSS diamana $\mathrm{N}$ adalah jumlah sampel, jika nilaistatistik >0,05 maka distribusi normal.

Tabel 3

Uji Normalitas

\begin{tabular}{lc}
\hline & Unst \\
& andar \\
& dized \\
& Resid \\
& ual \\
\hline $\mathrm{N}$ & 69 \\
Test Statistic & .128 \\
Asymp. Sig. (2-tailed) & $.007^{\mathrm{c}}$ \\
\multicolumn{1}{c}{ Sig. } & $.190^{\mathrm{d}}$ \\
\hline
\end{tabular}




\begin{tabular}{|c|c|c|c|}
\hline $\begin{array}{l}\text { Monte Carlo } \\
\text { Sig. (2- } \\
\text { tailed) }\end{array}$ & $\begin{array}{l}\text { 99\% Confidence } \\
\text { Interval }\end{array}$ & $\begin{array}{l}\text { Lo } \\
\text { wer } \\
\text { Bo } \\
\text { un } \\
\text { d } \\
\text { Up } \\
\text { per } \\
\text { Bo } \\
\text { un } \\
\text { d }\end{array}$ & 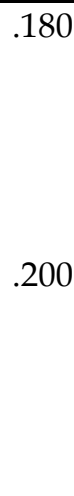 \\
\hline
\end{tabular}

\section{Uji Multikolinearitas}

Untuk mengetahui uji multikolinieritas dapat dilihat dengan menggunakan analisis SPSS dengan mleihat dari varian inflation factor dan nilai toleransi. Apabila varian inflatiction faktor lebih kecil dari 10 dan nilai toleran lebih tinggi 0,10 dapat disimpulkan uji multikolinieritas tidak valid

\section{Tabel 4}

Uji Multikoliniritas

Hasil tabel 4 di atas dapat diketahui bahwa nilai Tolerance semua variabel lebih besar dari 0,10 dan nilai VIF (Variance Inflation Factor) lebih kecil dari 10. Berdasarkan nilai di atas, dapat disimpulkan bahwa tidak terjadi multikolinieritas.

\section{Uji Heteroskedasititas}

Uji heteroskedasititas apabila varians dan residual dalam suatu pengamatan memiliki kejadian yang sama.

Tabel 5 Uji Heteroskedastisitas

\begin{tabular}{ll}
\hline \multicolumn{1}{c}{ Variabel } & Sig. \\
& \\
\hline Lingkungan Kerja & .216 \\
\hline Motivasi Kerja & .643 \\
\hline
\end{tabular}

Dari hasil output di atas dapat lingkungan kerja dan motivasi kerja, dengan Absollute residual memiliki nilai sigifikansi lebih besar dari 0,05 dapat disimpulkan yakni tidak terjadi masalah heteroskedastisitas pada model regresi.

\section{Uji Autokorelasi}

1. Hasil $D W<1,10$ ada autokorelasi

2. Hail DW 1,10 - 1,54 tanpa kesimpulan

3. Hasil DW 1,55 - 2,46 tidak ada autokorelasi

4. Hasil DW 2,46 - 2,90 tanpa kesimpulan

5. Hasil $\mathrm{DW}>2,91$ ada autokerolasi

Tabel 6

Uji Autokorelasi

\begin{tabular}{lcc}
\hline Variabel & \multicolumn{2}{c}{ Collinearity Statistics } \\
& $\begin{array}{c}\text { Toleranc } \\
\mathrm{e}\end{array}$ & VIF \\
\hline Lingkungan Kerja & .785 & 1.274 \\
(X1) & & \\
Motivasi Kerja (X2) & .785 & 1.274 \\
\hline
\end{tabular}

Durbin-Watson

$\frac{1.767}{\text { Nilai Durbin Watson 1,716 yang }}$
artinya DW berada diantara 1,55 s.d 2,46
sehingga tidak ada autokorelasi.

Analisis Data Menggunakan Regresi Linier Berganda 
Dari hasil analisis regresi linier berganda yang diperoleh dengan bantuan SPSS maka dapat menghasilkan nilai persamaan regresi sbg berikut:

Tabel 7

Hasil Uji Regresi Linear Berganda

$Y=5,383+0,379 \times 1$ $+0,622 \times 2+e$ satuan Motivasi Kerja (X2) akan mengakibatkan meningkatnya Semangat Kerja $(\mathrm{Y})$.

\section{Pengujian Hipotesis}

\section{Uji T}

Suatu variabel $X$ masih memberikan kontribusi secara signifiikan terhadap variabel terikat $\mathrm{Y}$. Pengujian dilakukan dengan membandingakan nilai

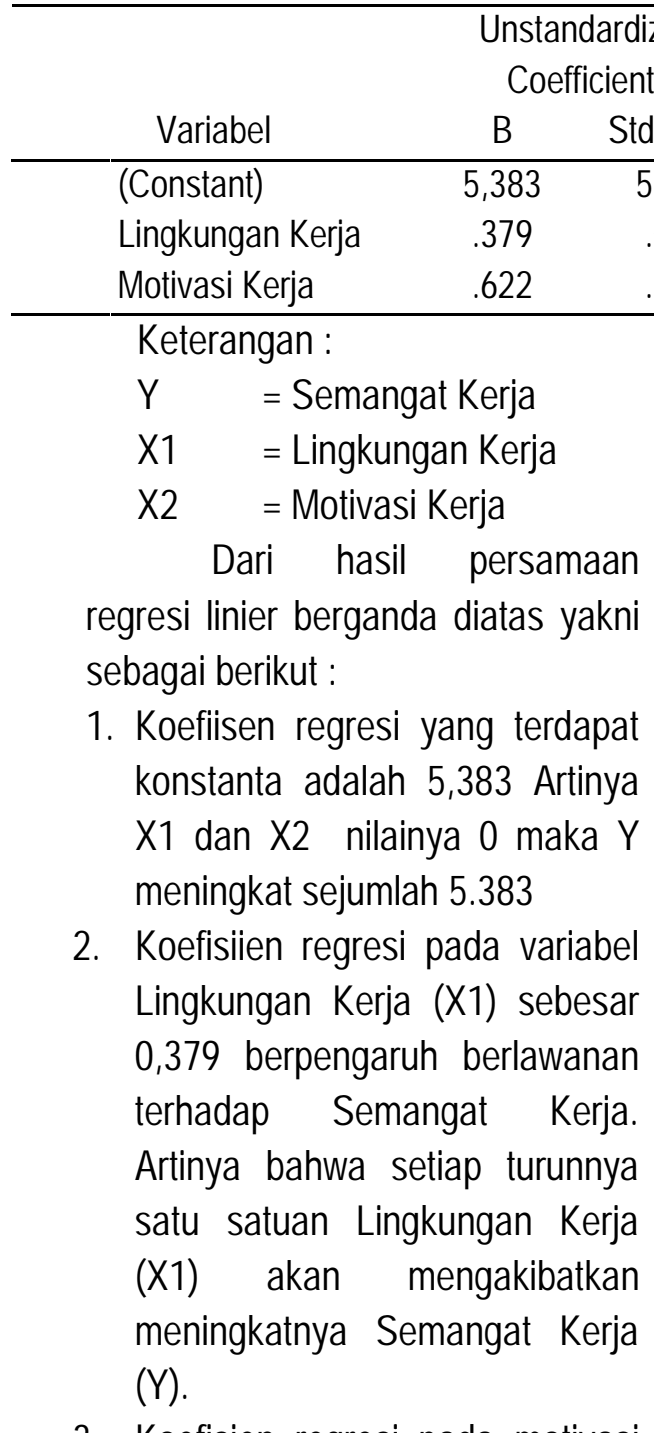

3. Koefisien regresi pada motivasi kerja (X2) sebesar 0.622 berpengaruh berlawanan terhadap Semangat Kerja (Y). Artinya setiap turunnya satu

Hasil tabel 8 diatas bahwa :

1. Pada variabel Lingkungan Kerja (X1), nilai signifikan dibawah 0,05 maka $\mathrm{HO}$ tidak valid artinya lingkungan kerja (X1) berpengaruh terhadap variabel Semangat Kerja $(\mathrm{Y})$.

2. Variabel motivasi kerja (X2), nilai signifikikan dibawah dari 0,05 maka $\mathrm{HO}$ tidak valid artinya motivasi kerja (X2) berpengaruh terhadap Semangat Kerja (Y).

\section{Uji F}

Uji-f digunakan untuk mengetahui apakah variable Lingkungan Kerja $\left(X_{1}\right)$. Motivasi Kerja $\left(X_{2}\right)$ berpengaruh secara 
simultan terhadap variable Semangat $\operatorname{Kerja}(Y)$.

Tabel 9

Hasil Uji F

\begin{tabular}{lll}
\hline & $\mathrm{F}$ & Sig. \\
\hline Regression & 50.270 &, $000^{\mathrm{b}}$
\end{tabular}

Hasil $0,002<0,05$, dapat diambil keputusan bahwa $\mathrm{HO}$ tidak reilebel. Hal ini berarti variabel X1 dan X2 secara bersama-sama berpengaruh terhadap $Y$.

\section{SIMPULAN}

Maka dapat disimpilkan hasil dari penelitian yakni:

1. Lingkungan kerja berpengaruh terhadap semangat kerja karyawan PT. Alkonusa Teknik Interkon Surabaya.

2. Motivasi kerja berpengaruh terhadap semangat kerja karyawan PT. Alkonusa Teknik Interkon Surabaya.

\section{IMPLIKASI}

Penelitian ini menggambarkan pengaruh antara " motivasi dan lingkungan dan semangat kerja "', dimana variabel likngkungan kerja lebih mendominasi terhadap semangat kerja karyawan PT. Alkonusa Teknik Interkon Surabaya.

Selain lingkungan kerja dan motivasi kerja, PT. Alkonusa Teknik Interkon juga harus memperhatikan dan mengoptimalkan aspek-aspek linngkungan kerja..

\section{KETERBATASAN PENELITIAN}

Penelitian ini dilakukan dengan apa adanya dan kekurangan sebagai mestinya, , sedangkan masih banyak faktor lain yang memperngaruhi Semangat Kerja karyawan, adanya kekurangan penelitian dengan menggunakan kusioner yaitu terkadang jawaban yang diberikan oleh sampel tidak menunjukkan keadaan yang sesungguhny

\section{SARAN}

- Hasil ini juga menunjukkan bahwa masih terdapat faktor-faktor lain yang mempengaruhi semangat kerja karyawan. Oleh karena itu peneliti menyarankan bagi perusahaan atau pihak lain yang akan mengadakan penelitian lingkungan kerja karyawan dan motivasi kerja karyawan faktor yang dapat mempengaruhi semangat kerja karyawan.

- Perlu membina hubungan hubungan kerjasama antara karyawan dalam pelaksanaan tugas sehingga tidak ada rasa iri dan individual. Dengan demikian, tugas diberikan dapat diselesaikan dengan rasa senang hati. 